\title{
NILO PREVIDI E O MEIO ARTÍSTICO CURITIBANO DA DÉCADA DE 1960
}

\author{
NILO PREVIDI AND ARTISTIC MILIEU OF THE 1960S \\ CURITIBANO
}

\author{
Carla Emilia Nascimento* \\ Rosane Kaminski**
}

\begin{abstract}
Resumo: O presente artigo pretende discutir alguns aspectos das escolhas estéticas do artista Nilo Previdi (1913-1982), no contexto de Curitiba na década de 1960. A análise específica de três obras relacionadas aos anos 60, somada a outras obras de outros períodos e ao discurso dele e sobre ele, extraído dos jornais da época e de entrevistas realizadas com outros agentes contemporâneos ao artista, compõem esta discussão que se desdobra na tentativa de compreender a sua visibilidade no meio artístico e o espaço ocupado por ele no cenário local. De certa forma, esta análise acaba expondo aspectos do cenário cultural da época, onde opções ofertadas e escolhas feitas acabam por demarcar lugares no meio artístico.
\end{abstract}

Palavras-chave: Arte moderna paranaense. Arte engajada. Arte abstrata.

\begin{abstract}
This article aims to introduce and discuss some aspects the aesthetic choice of the artist Previdi Nilo (1913-1982), in the context of Curitiba in the 1960s. The specific analysis of three works related to the 60 , along with other works from periods and discourse him and about him, extracted from newspapers of the era and interviews with other agents to the contemporary artist, make up this discussion that unfolds in an attempt to understand their visibility in the arts and the space occupied by it on the local scene. In a way, this analysis has just exposing the cultural setting of the time, which offered options and choices ultimately determining places in the arts.
\end{abstract}

Keywords: Modern art Paraná. Activism art. Abstract art.

\footnotetext{
* Mestranda no Programa de Pós-Graduação em História da Universidade Federal do Paraná (UFPR). Bolsista da CAPES. E-mail: carlaemilia.nascimento1@gmail.com

** Professora na Universidade Federal do Paraná (UFPR).

E-mail: rosane.kaminski@gmail.com
} 
Este artigo tem como objeto de estudo as escolhas estéticas de Nilo Previdi (1913-1982) nos anos 1960, artista curitibano até hoje pouco valorizado pela história da arte. ${ }^{1} \mathrm{Na}$ tentativa de compreender melhor a atuação de Previdi, são analisadas algumas de suas obras, mas também são explorados outros documentos históricos, como entrevistas e periódicos impressos. Ao articular a análise das imagens artísticas ao estudo desses registros históricos escritos $\mathrm{e}$ orais, a imagem, seja ela uma obra de arte ou não, produzida a partir de qualquer meio mecânico ou técnico, requer um exercício interpretativo que considere as suas especificidades formais e semânticas, além de ponderar seus possíveis significados históricos diante do seu tempo.

Essa interpretação do objeto visual, ou, como prefere Peter Burke do "indício" visual, pois nada na imagem é evidente e os sentidos são construídos, se faz nesta proposta, a partir do cruzamento entre a obra de arte e as informações disponíveis sobre o contexto de produção da mesma e do seu produtor, o artista. ${ }^{2}$ O procedimento adotado neste texto busca conciliar, de forma geral, os estudos feitos sobre a leitura da obra de arte à proposta interpretativa apresentada por Baxandall, cuja intenção é buscar no tempo em que foi produzida uma obra as condições que a levaram a ser da forma como se apresenta. ${ }^{3}$

O repertório teórico sobre a leitura de imagens, de Panofsky, Warburg e Gombrich, somados e pensados a partir do que possuem em comum, leva a considerar a obra produzida em sua cultura específica, considerando os elementos estéticos (cuja análise puramente formal se torna insuficiente), mas também a compreensão da situação histórica e a noção de que a obra não se resume à personalidade do artista. ${ }^{4}$ Neste ponto, Baxandall propõe que se pense a obra de arte como um objeto de arte produzida de forma intencional, pois:

[...] o pintor ou o autor de um artefato histórico qualquer se defronta com um problema cuja solução concreta acabada é o objeto que ele nos apresenta. A fim de compreendêlo, tentamos reconstruir ao mesmo tempo o problema específico que o autor queria resolver e as circunstâncias específicas que o levaram a produzir o objeto tal como é. Mas a reconstrução não refaz a experiência interna do autor; ela sempre será uma simplificação limitada ao que é conceitualizável, mesmo que opere em uma estreita relação como o quadro em si, o que nos proporciona, entre outras coisas, modos de perceber e sentir. ${ }^{5}$

Esta busca pela intencionalidade do tempo, para usar uma expressão do autor, não pode ser feita desconsiderando as principais discussões presentes no momento do contexto em questão. Portanto, neste texto buscaremos avaliar algumas obras de Nilo Previdi considerando as suas características e articulando-as ao lugar social que o artista ocupava na cidade de Curitiba quando 
as produziu. É importante enfatizar que apesar do estudo estar concentrado na década de 1960, algumas obras de Previdi feitas nas décadas anteriores são apresentadas, pois assim é possível pensar na formação do pensamento do artista e nas suas tomadas de decisão na década de 60 .

\section{DE ONDE E DE QUEM SE FALA}

Este texto adota marcos para se falar de arte moderna no Paraná. Para tanto considera-se que as décadas de 1950 e 60 representam o período de "consolidação da arte moderna paranaense", conforme Freitas ${ }^{6}$; e de que esta mesma concepção de arte moderna sofre uma segunda ruptura a partir de 1962 com a introdução e posterior hegemonia da arte abstrata no cenário local, de acordo com Camargo.?

Fala-se da cidade de Curitiba, entre as décadas de 1950 e especialmente, 1960. As obras escolhidas são do artista curitibano Nilo Previdi, cuja trajetória artística expõe aspectos da própria história da arte paranaense, pois ele esteve envolvido com as principais instituições de arte da cidade no período em que foram formadas - a Escola de Música e Belas Artes (EMBAP), formada em 1944; o Salão Paranaense de Belas Artes (1948), e pode-se falar também nos grupos alternativos como o Círculo de Artes Plásticas (1958), a Cocaco (1957) e a Garaginha (1951) - além de ser um agente ativo no debate artístico, cuja presença nos jornais locais é constante até o início da década de 60, além de sua atuação no Centro de Gravura do Paraná, instituição que presidiu de 1950 até início de 1970.

Inicialmente, cabe enfatizar que a década de 60 no Paraná foi marcada por modificações no meio artístico, propiciando o início da valorização e crescimento da arte abstrata no Estado. Entenda-se pelo meio artístico, a funcionalidade das instituições provedoras da arte e suas relações com o resto da sociedade local. ${ }^{8}$

Há ainda de se considerar o projeto modernizador de Curitiba, que ganha visibilidade em 1950, em razão das comemorações do centenário de emancipação do Estado do Paraná. As obras urbanísticas que iniciaram em uma década, adentraram pela seguinte, transformando não apenas o visual da cidade, mas a vida das pessoas. É possível pensar em um ideal coletivo de modernidade como um projeto, para citar Belting, que ao expor o desenvolvimento da História da arte, associa esta e a ideia de estilo à modernidade, considerando que uma sociedade moderna exige uma nova arte para o novo estilo de vida, onde inicialmente a arquitetura e o design mudariam o espaço vital, esperando que o mesmo acontecesse com os homens. ${ }^{9}$

A partir do exposto, pelo menos duas considerações são importantes para este artigo. A primeira delas consiste em entender que a vontade da sociedade, 
em geral pode ser entendida como a vontade de um grupo detentor de poder na ocasião, agindo também através do aparato cultural. Conforme o entendimento de Camargo, na sua pesquisa sobre o abstracionismo no Paraná:

As escolhas são feitas a partir de uma gama de possibilidades, dentre as quais fulgura o modelo buscado pelos agentes culturais, seja por aspiração a uma suposta "universalidade", seja por adesão a um dado modelo cultural dominante... ${ }^{10}$

Outra questão diz respeito aos projetos éticos/políticos que podem ser pensados junto com o projeto de modernidade e que repercutiram fortemente nos meios estéticos, como por exemplo, a própria noção do engajamento social e que no contexto acima descrito por Camargo, representou a oposição ao modelo de cultura dominante, e se caracterizou, no caso do artista Nilo Previdi, pela preferência à figuração em detrimento da abstração.

Não fosse em um universo de possibilidades de escolhas, ficaria difícil justificar obras figurativas em um contexto de valorização da arte abstrata. Desta forma, as três principais obras do artista Nilo Previdi a serem aqui analisadas são da década de 60 e não são obras abstratas, mas carregam características modernas pela forma como foram executadas e pelo enfoque dado à temática.

Figura 1 - Sem título, 1961

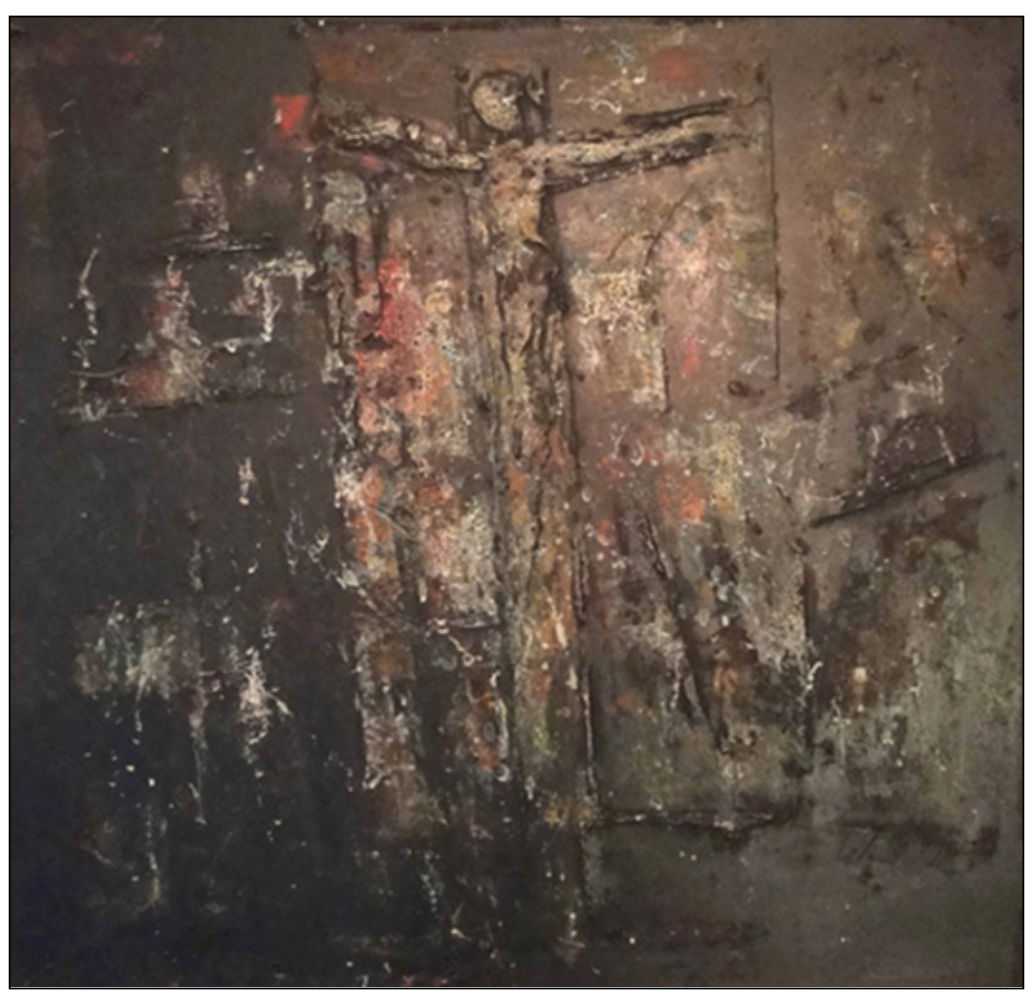

Fonte: Acervo Airton Cornelsen. Fotografia: Carla Emilia Nascimento. 
A primeira obra (Figura 1) traz a imagem de um corpo crucificado. Este trabalho de 1961 chama a atenção pela espessa quantidade de massa utilizada para trabalhar o corpo, quase um alto-relevo. É uma obra bastante escura, onde a figuração reside no corpo, praticamente esculpido com a massa de tinta.

Um segundo trabalho (Figura 2) data de 1962 e é uma cena do cotidiano urbano, onde se destaca a construção de prédios e a verticalização da cidade, representando o alargamento da rua Marechal Deodoro, região central de Curitiba. ${ }^{11}$ Nota-se também a circulação de pessoas pela cidade.

Figura 2 - Sem título, 1962

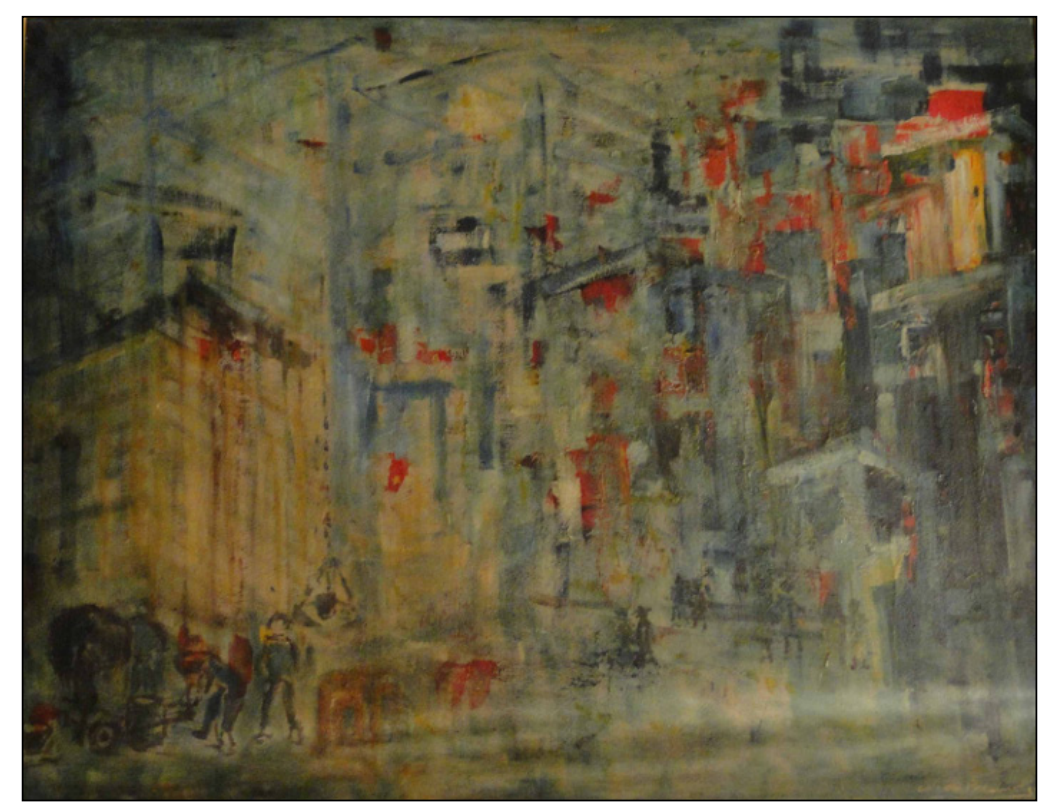

Fonte: Acervo particular. Fotografia: Carla Emilia Nascimento.

A pintura de 1964 (Figura 3) traz um tema bastante recorrente na obra do artista, a representação de mulheres lavadeiras. São tipos sociais que Previdi elabora a partir de formas recorrentes em suas obras que seguem essa temática, como a representação das personagens de costas, os braços erguidos sendo prolongados pelas roupas a serem estendidas, as poucas linhas para definir os corpos, geralmente em forma de retângulos ou triangulares, onde corpo e vestidos se fundem. 
Figura 3 - Sem título, 1964

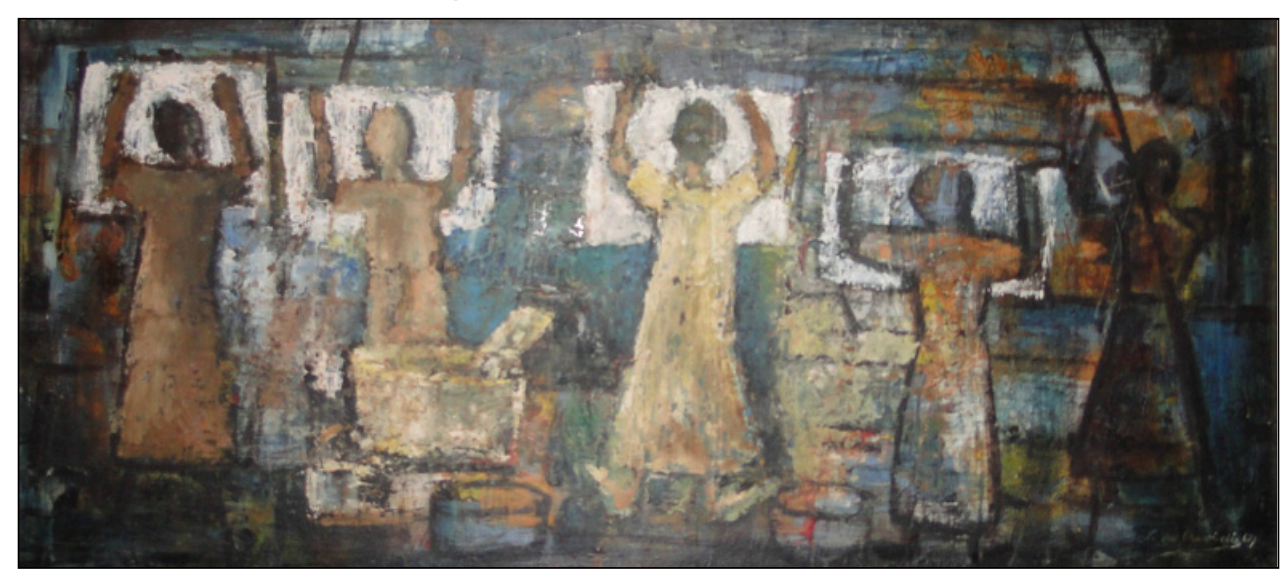

Fonte: Acervo Airton Cornelsen. Fotografia: Carla Emilia Nascimento.

As três obras em conjunto (Figuras 1, 2 e 3) permitem pensar sobre algumas permanências e rupturas trazidas pelo desenvolvimento da cidade, pela noção de progresso e modernidade. O trabalho humilde das lavadeiras aparece como uma permanência, convivendo lado a lado com o progresso: as ruas asfaltadas, as praças, os teatros, a biblioteca os cafés recém inaugurados. $\mathrm{O}$ desejo de modernização também estética transparece nos recursos expressivos utilizados pelo artista, tais quais a tinta empastada e a deformação e/ou estilização das figuras.

Voltando a atenção novamente para as Figuras 2 e 3, observadas em conjunto, observa-se uma exaltação à urbanidade, e ao lado, indivíduos desprovidos do acesso a essa vida moderna, cuja maior expressão se encontra na representação do trabalho, da condição social. Conforme já mencionado, a Figura 1 apresenta uma pessoa crucificada, que pode ser qualquer uma, até mesmo Jesus Cristo. Mas na obra, nada expressa santidade ou religiosidade, além da presença do símbolo que é a cruz. Trata-se de uma pessoa sem rosto, mas numa condição que referência ao sofrimento ou até mesmo ao sacrifício.

Ao escolher estas três obras para interpretar a atuação de Previdi na década de 60, algumas evidências ficam claras. Elas são anunciadas a seguir, pois a partir delas será possível pensar nas escolhas feitas pelo artista e em que medida elas definiram o lugar dele e o modo como passou a ser visto na sociedade em que viveu. Ao longo do desenvolvimento desta pesquisa, e durante o levantamento das obras produzidas por Previdi, não foi encontrada nenhuma obra abstrata realizada por ele na década de 60 . Pode-se afirmar, pela escolha figurativa do artista, que ele não foi adepto da arte abstrata que vinha se fortalecendo no meio artístico curitibano; logo, o fato de que Previdi ficou fora do certame da arte oficial na década de 60 pode ter sido ou o efeito de uma exclusão do meio artístico, ou opção do próprio artista. ${ }^{12}$ 
A temática social é algo que prevalece em sua obra, mesmo nos momentos em que as discussões locais se voltam para um estudo formal em detrimento do conteúdo da obra; este é um fato que leva a pensar nas convicções ideológicas do artista, porque até o início dos anos 1960 sua característica marcante era participar do debate artístico e publicar suas opiniões nos jornais locais, e não se calar como se verifica na segunda metade daquela década. É interessante pensar a opção figurativa do artista relacionada à sua opção política, numa relação ideológica que não se deu da mesma forma com outros artistas que em determinados momentos foram figurativos, ou aderiram na época ao partido comunista por uma questão filosófica, mudando em seguida. ${ }^{13}$ Mas há uma variedade na representação de temas e nas formas de representação, ora com uma pintura forte pelo empastamento, ora pela escolha de representar o tema privilegiando o uso de manchas de cor, ou o vigor das pinceladas e contornos de tendência expressionista; o que instiga a considerar a versatilidade e a experimentação do artista, e também a possibilidade de que Previdi também pudesse não ser totalmente avesso à abstração, mesmo tendo um perfil engajado.

\section{A CONSTRUÇÃO DA FIGURA MODERNA E FIGURATIVA DE PREVIDI: UM PREÂMBULO PARA OS ACONTECIMENTOS DA DÉCADA DE 1960}

Os acontecimentos que ocorreram durante as décadas de 1950 e 60 no cenário artístico de Curitiba exigiram tomadas de posição, que vieram a ser fundamentais para o modo como os artistas envolvidos com a problemática da arte naquele tempo passariam a ser vistos.

Antes de discorrer sobre a obra do artista na década de 1960 e sua aversão e não adesão à abstração é conveniente apresentar alguns aspectos que justifiquem o caráter moderno de Previdi. ${ }^{14}$ Para tanto, vejamos duas obras do artista, uma de 1943 e outra de 1957, respectivamente a Figura 4 e a Figura 5.

O intuito é enfatizar as alterações na obra do artista e relacioná-las as mudanças de pensamento ocorridas na formação da concepção de arte moderna no Paraná. Ao fazer este exercício, é interessante sempre ter em mente as três imagens iniciais, produzidas em 1960 e já comentadas: o crucificado, a cidade e as lavadeiras. Contrapondo aquelas três obras à natureza-morta (Figura 4), percebe-se nesta a existência de uma preocupação naturalista com o tema, expressa na forma como a composição foi elaborada, considerando a forma delicada de colocação da tinta, a disposição das frutas dentro e fora da fruteira, o cuidado com a posição do pano sob as laranjas, dados que permitem identificar planos de profundidade, como também o jogo de luz e sombra que dá forma ao drapeado do tecido e sugere a tridimensionalidade do motivo. 
Figura 4 - Sem título, 1943

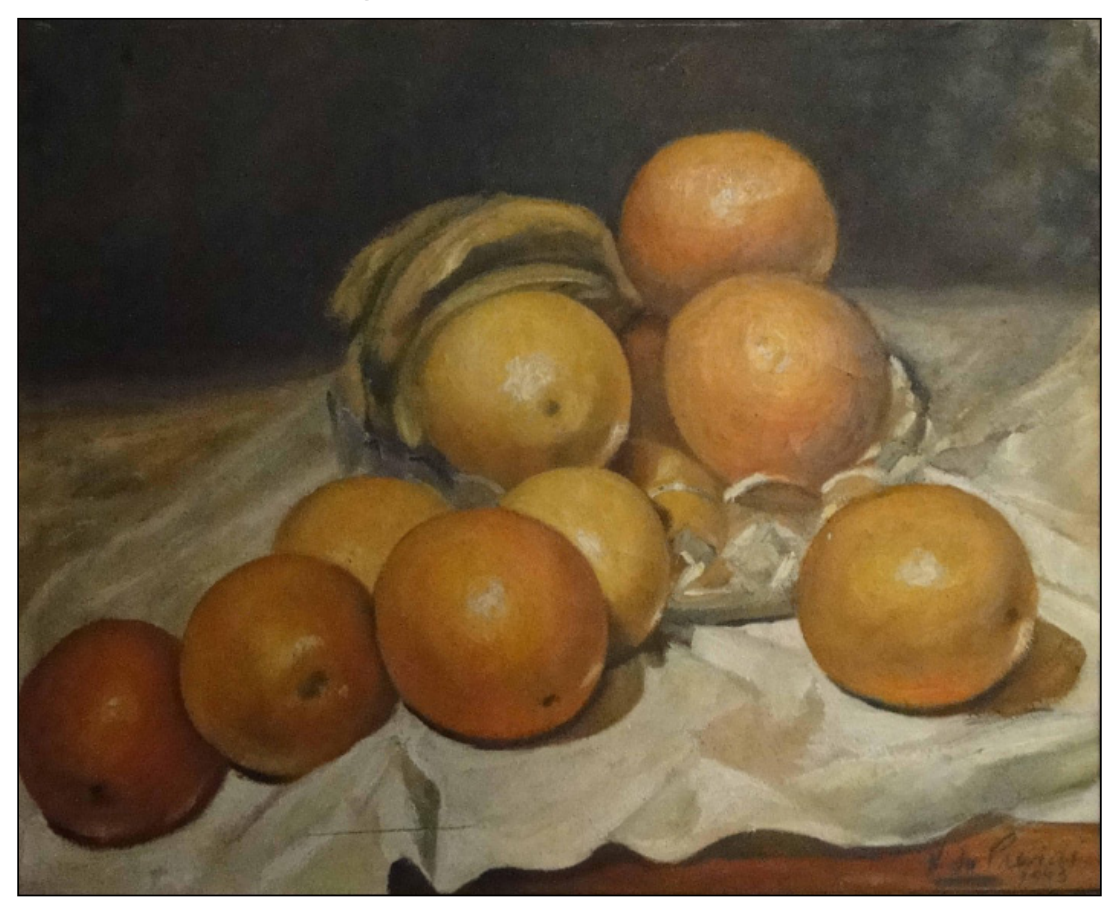

Fonte: Acervo Simara Previdi. Fotografia: Carla Emilia Nascimento.

A natureza-morta da década de 1940 é um exemplo do trabalho artístico do pintor em um momento de prática de pintura cuja preocupação é com a execução de determinadas regras, capazes de conferir à pintura um aspecto naturalista. É um exemplo de uma produção realizada dentro dos padrões de uma tradição acadêmica que nos anos 1940 eram a principal referência aos artistas residentes em Curitiba. É interessante observar que em 1943, não havia ainda o aparato institucional que passaria a existir na cidade, quase uma década depois, alimentado pelo desenvolvimento do Salão de Belas Artes, inaugurado em 1944, e pela Escola de Belas Artes (EMPAB), em 1948. Previdi fazia aulas com outros artistas, desde 1930, segundo consta em sua biografia. Foram seus mestres Erbo Stenzel, João Turin, Oswaldo Lopes, que foram discípulos de Mariano de Lima e Alfredo Andersen, além de Guido Viaro, que se tornaria o mestre da geração dos artistas modernos da década de 1950.

É possível pensarmos como esses mestres atuaram como referências para Previdi, considerando a ação dos primeiros professores mais voltada ao ensino clássico e tradicional, enquanto Viaro representava uma tendência mais livre, se ousarmos pensar no contexto da arte nacional. Nesse sentido, observa-se que a primeira natureza-morta é um trabalho que parece não diferir muito do que se esperava para época, uma vez que na cidade não existiam informações ou referências abundantes sobre a arte que se fazia fora do Paraná. ${ }^{15}$ 
Figura 5 - Sem título, 1957

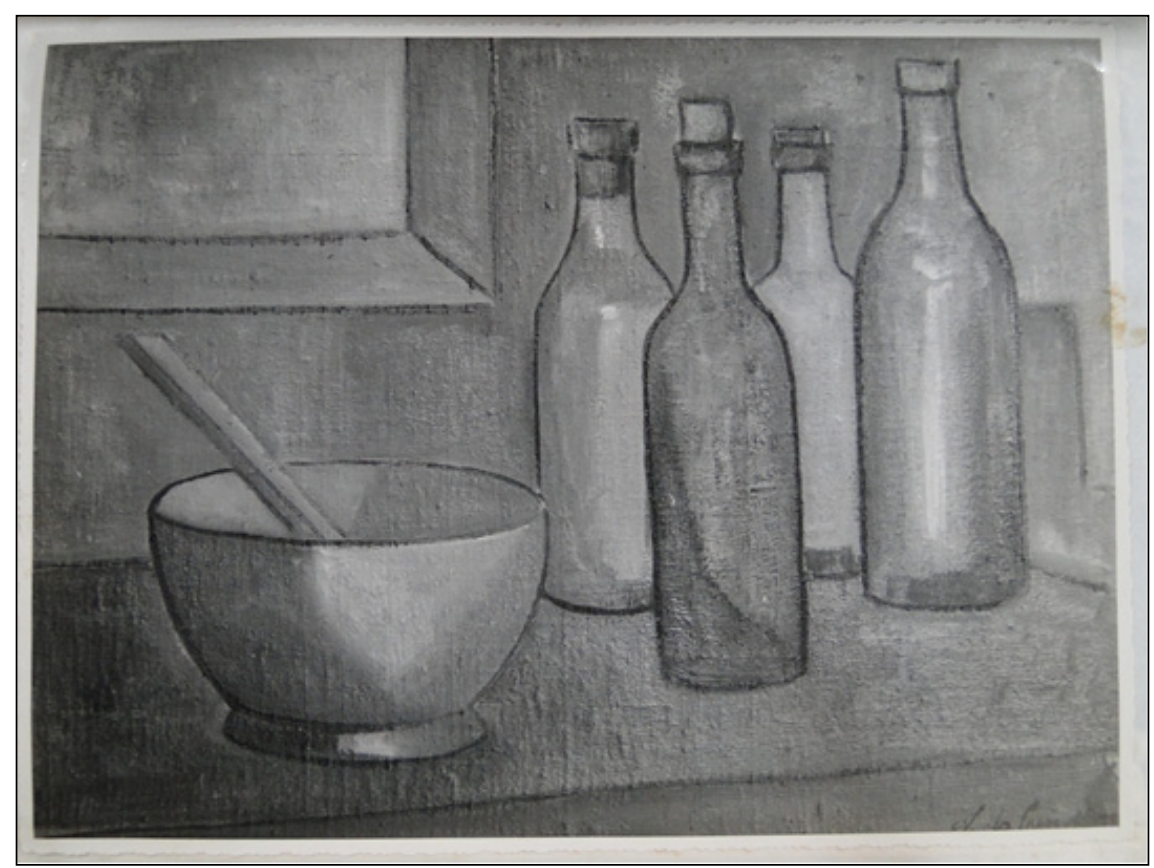

Fonte: Acervo do MAC, pasta do XIV Salão Paranaense.

Já a natureza-morta da década de 1950 (Figura 5), é significativa pelas modificações no aspecto formal do trabalho do artista, de onde se destaca uma preocupação mais ligada ao desenho da composição do que a representação naturalista do tema. Além da ausência das cores na imagem, os contrastes de luz e sombra são amenizados pela presença de contornos nas figuras, e aquele efeito de gradação tonal que conferia a profundidade na imagem anterior é aqui substituído por uma organização mais geométrica do espaço. Certamente em termos de aspectos formais modernos, em comparação com as três obras iniciais, ainda é um trabalho tímido e modesto nas inovações, porém há de se considerar as tênues modificações que não se resumem apenas a um amadurecimento artístico pessoal de uma década para outra mas, agregado a ele, essa transformação pictórica diz respeito a uma mudança de concepção de arte, como parte integrante de uma concepção de visão de mundo, compartilhada com outros artistas. Não se trata exatamente de um "espírito do tempo", noção criticada por Gombrich, mas de entender o processo do qual o artista fez parte como integrante da mesma sociedade. ${ }^{16}$

Os jornais da década de 1950 permitem verificar o debate instaurado em torno da discussão de uma arte, onde se percebe a predominância de um senso de modernidade emergente. Em um artigo extraído do Jornal O Dia, de 16 de dezembro de 1956, afirma-se que pintores novos só devem participar do salão de arte se a obra for velha! Entenda-se por velha a obra acadêmica, semelhante à primeira natureza-morta de Previdi apresentada. Ainda no mesmo 
artigo, ironicamente há uma definição para o pintor acadêmico: "É aquele que pinta como faria seu tetravô, mas não teria coragem de usar as instalações sanitárias que ele usava". ${ }^{17}$

Outro diferencial importante é a história que marca esta naturezamorta "moderna" (Figura 5) e que lhe confere um valor simbólico. A obra, cuja presença material se reduz hoje a uma fotografia preto e branco foi apresentada à seleção julgadora do XIV Salão de Artes Paranaense, em 1957, sendo supostamente uma das obras componentes do Salão dos Pré-Julgados, que se constituiu em um salão à parte do XIV Salão Oficial, formado pelas obras dos artistas que ficaram insatisfeitos com as decisões do júri e retiraram suas obras. ${ }^{18}$

A participação de Previdi na exposição dos Pré-Julgados o coloca ao lado daqueles artistas descontentes com o resultado do júri no salão de arte oficial, onde as premiações contemplavam ao tipo de arte mais ligada ao academicismo. Junto com outros artistas, ele também passou a ser chamado para o debate a respeito das regras dos próximos salões, já caracterizado como artista moderno.

É uma espécie de marco que a partir daquele momento o estabelece como um artista moderno. Certamente não o poderia ser apenas por ter participação neste salão específico, mas também por outros motivos, que podem estar na base das três obras principais analisadas. Entre eles, pode-se citar o ensino que o artista recebeu além da EMBAP, como as aulas de Gravura com Poty Lazzaroto (1950); a experiência que Previdi teve no serviço público como pintor de bondes, o que propiciou as experimentações com a pintura a base de tinta auto-motiva (piroxilina) (1934), sua atuação como paisagista no DER (1960) que de certa forma expandiu a sua atuação artística; a participação de Previdi nos grupos alternativos de arte como a Cocaco, a Garaginha e o Círculo de Artes Plásticas (anos 50/60); a participação de Previdi como expositor na I Bienal de São Paulo (1951) ${ }^{19}$; a escolha pela figuração de temática social de tendência expressionista e a adesão à noção de engajamento social, ideias difundidas durante os anos 60.

De acordo com a análise das obras apresentadas, em relação à história da arte no Paraná, constatou-se que a produção artística de Previdi foi correspondente a solucionar alguns impasses da época - especificamente na década de 1950 - como por exemplo, a necessidade da suplantação da arte acadêmica e com isso a abertura para a experimentação de novos materiais e técnicas (como a piroxilina e o empastamento) bem como a apresentação de novos temas, tais quais os de enfoque social (vide Figura 3). A ênfase na temática social foi correspondente à produção artística de outras regiões do Brasil, e em Previdi, ainda se estende para um aspecto não analisado neste texto que foi a sua atuação como gravador, além das suas pinturas. ${ }^{20}$ 
Considerando o campo de forças e conflitos do meio artístico, como analisado por Camargo, nota-se a presença de Previdi na década de 1950 , inserido num grupo de "renovadores da arte paranaense", muito bem conformado com todos os "ritos" instituídos pelo campo artístico, ao mesmo tempo em que se empenhava em abrir mais espaço para os artistas de tendência moderna. ${ }^{21}$

Mas de uma década para outra, a modernidade que Previdi ajudou a instituir no meio artístico se mostrou ultrapassada, não mais condizente com a nova visão de sociedade moderna, legitimada agora pela força dos agentes culturais que estavam à frente de uma das principais instituições de arte da cidade, o Salão Paranaense, com uma política de favorecimento à arte abstrata. Se o rótulo de moderno não lhe coube mais, pelo seu posicionamento contrário a essa nova política, o rótulo de Previdi como engajado foi o que permaneceu e de certa forma o que se tornou mais visível neste período, chegando a representar uma antítese do que é ser moderno.

\section{ESCOLHAS ESTÉTICAS E POLÍTICAS DE PREVIDI NOS ANOS 1960}

A partir da discussão apresentada e com a leitura de Camargo ${ }^{22}$, verifica-se que as mudanças nas concepções modernas em arte no Paraná estão relacionadas, também às modificações internas realizadas dentro do Salão Paranaense. Se desde a sua criação, em 1944, até o final da década de 1950 o Salão era um certame pautado predominantemente em valores artísticos acadêmicos, nos anos 1960 essa situação se modifica. Constata-se que a partir de 1961, no governo de Ney Braga, a pintura abstrata passa a ser legitimada através da ação de críticos de arte, intelectuais e artistas adeptos a esta nova linguagem, que passam a dirigir o Departamento de Cultura e consequentemente o próprio Salão. Neste momento a figura do diretor cultural Ennio Marques Ferreira (que participou como artista do Salão dos Pré-Julgados, sendo um deles), do crítico de arte Eduardo Rocha Virmond e do artista recém chegado da Europa Fernando Velloso (também um artista participante do Salão dos Pré-julgados) são importantes para este processo de incentivo e valorização da arte abstrata.

Mas é importante enfatizar que esta mudança de concepção de arte dentro do Salão Paranaense não se deu de forma passiva entre os artistas, incluindo aqueles que uma década antes reivindicavam o título de modernos, como Nilo Previdi. Mais uma vez a discussão avança pelos jornais locais como no seguinte exemplo, em que Ennio Marques em entrevista ao Jornal O Estado do Paraná, de 21 de dezembro de 1963, responde as críticas feitas à hegemonia da arte abstrata no XX Salão Paranaense de 1963: 


\begin{abstract}
Alguns intelectuais, bitolados por uma radicalização sem nenhum sentido, se aliaram a uns poucos acadêmicos nessa campanha nada construtiva, demonstrando um total desconhecimento do nosso ambiente artístico e das dificuldades por que passa esse grupo de moços que preferem continuar com suas experiências de vanguarda a satisfazer o gosto duvidoso do tradicional mercado comprador. [...] Acusam de inconseqüente por eles a arte chamada de "alienada", isto é, aquela que foge da linha rígida seguida pelos sectários da esquerda. As artes plásticas deveriam ser "engajadas" precisariam conter aquilo que subjetivamente seria uma "mensagem" Desfilam uma série de chavões estereotipados que nada tem a ver com a arte. ${ }^{23}$
\end{abstract}

$\mathrm{Na}$ declaração acima, constata-se parte da problemática da arte paranaense do período, enfatizando-se o embate existente entre arte abstrata e a arte engajada, uma associada à alienação (por parte dos artistas paranaenses descontentes com o abstracionismo) e a outra ao esquerdismo político de tendência figurativa. Ennio Marques Ferreira não cita nomes, mas o desenrolar do debate instituído pelos jornais deixa claro que do lado oposto à política do Departamento de Cultura está Nilo Previdi, cujas obras analisadas no decorrer deste texto ajudam a compreender a concepção de arte defendida pelo artista. Para Previdi, a arte devia ser antes de tudo o reflexo do sentimento do povo e não uma forma estereotipada de arte que ele considerava enlatada e pré-fabricada. ${ }^{24}$

Nilo Previdi foi um dos artistas responsáveis por provocar mudanças nas concepções da arte paranaense durante a década de 1950, propondo especialmente alterações no Salão Paranaense, a fim de que ele e os outros artistas que reivindicavam o status de artistas modernos pudessem participar dos salões de arte locais. Entretanto, na década de 1960, com a hegemonia crescente da abstração, no Salão de arte oficial, Previdi se afasta cada vez mais dos espaços institucionais voltados à arte moderna, e dedica-se quase integralmente ao Centro de Gravura, sem o auxilio dos outros professores.

O Centro de Gravura do Paraná tinha sua sede no subsolo da EMBAP, sendo dirigido praticamente desde o início da década de 1950 por Previdi. Nasceu a partir da inspiração do Clube de Gravura Gaúcho, cujo maior representante foi Carlos Scliar, mas em Curitiba não chegou a funcionar de acordo com o mesmo sistema dos outros clubes, mediante as vendas das gravuras. A ideia de um Clube, que reuniria artistas, acabou se transformando em uma espécie de escola.

Até 1959, de acordo com Alcy Xavier, tratava-se de um atelier livre. Xavier, artista que trabalhou junto com Previdi, afirma que o Centro de Gravura era um espaço onde não existia uma preocupação doutrinal e o intuito era de ensinar a gravura e na medida do possível dar noções de estética e história da 
arte. Xavier deu aulas lá, ensinando Estética e Desenho, enquanto Esmeraldo Blasi ocupava-se da História da Arte e Previdi era responsável pela prática da gravura. Xavier confirma que eles tiveram cerca de 40 alunos, mas nada foi registrado, não havia interesse por parte dos professores em preservar a história do lugar.

Neste período, enfim, acentua-se o aspecto engajado da atuação de Previdi, não apenas na temática social de suas obras, mas principalmente em sua atuação social, pois ele passa a utilizar o porão da EMBAP para discutir ideias políticas e recolher as pessoas das ruas, dando-lhes um local onde pudessem se abrigar. Enquanto abria-se um espaço de assistência social, ao mesmo tempo funcionava a escola de gravura, em geral com um ensino e produção voltados à arte de temática figurativa e social. $\mathrm{O}$ Centro de Gravura funcionou até o início dos anos 70, ano em que o espaço ocupado pela escola de gravura é reivindicado pela própria EMBAP.

Para concluir este texto, observa-se que as transformações na mentalidade dos artistas da época podem ser acompanhadas por um estudo mais profundo da obra do próprio artista, associado à compreensão de que elas, as obras de arte, são também respostas a problemas surgidos no contexto, e que o fato de o artista não ter aderido à abstração na década de 1960 é devido a causas (e escolhas) bem específicas. No caso de Previdi, a questão ideológica, de pertencimento a um partido de esquerda, associado ao desenvolvimento de um trabalho engajado, somado à aversão às elites locais - que por sua vez comandaram o meio artístico na década de 1960 introduzindo e desenvolvendo a abstração no Estado - fornecem indícios que podem justificar as escolhas feitas pelos artistas nas décadas analisadas e entender tanto a posição assumida por ele, como a sua imagem ao longo das décadas de 1950 e 60.

\section{NOTAS}

1 Nilo Previdi nasceu em Curitiba em 28 jul.1913. Filho de imigrantes italianos foi pintor de bondes, professor de gravura, artista plástico e também paisagista. Iniciou-se no aprendizado da arte na década de 1930. Em 1944 adquiriu o primeiro título da carreira no I Salão de Arte Paranaense com uma menção honrosa. Formou-se na Escola de Música e Belas Artes do Paraná (EMBAP) na década de 1960, mas desde 1950 esteve à frente do Clube de Gravura do Paraná, um espaço livre de arte onde se praticava a gravura e que funcionou no porão da EMBAP até inicio da década de 1970. Ao lado dos pintores modernos do Paraná na década de 1950 foi atuante no meio artístico. Filiado ao partido comunista, era também conhecido por seu aspecto engajado e militante. Durante a década de 1960 foi um defensor da arte figurativa e um crítico, tanto da arte abstrata quanto da política cultural vigente no Estado naquele período. Faleceu em 06/03/1982 deixando uma obra diversificada, porém fortemente marcada pelo aspecto figurativo e social de suas obras.

2 BURKE, Peter. Testemunha ocular: história e imagem. Bauru, São Paulo: EDUSC, 2004.

3 BAXANDALL, Michel. Padrões de intenção: a explicação histórica dos quadros. Companhia das Letras: 2006. 
${ }^{4} \mathrm{O}$ termo iconografia refere-se à disciplina da História da Arte que trata da identificação, descrição, classificação e interpretação do tema das artes figurativas, sendo que iconologia foi o termo proposto por Erwin Panofisky para uma abordagem mais ampla dos temas da arte, de forma a compreender o significado da obra em seu contexto. Entre outros estudiosos, Aby Warburg destaca-se por entender a iconografia como uma forma possível para a compreensão de uma situação histórica a partir de fontes figurativas, recusando-se a fazer leituras puramente estéticas, ampliando a leitura visual para além da obra de arte e para além do campo de atuação dos historiadores da arte. Contexto e alternativas disponíveis no tempo e espaço da realização das obras também são importantes para Gombrich que afirma que "a forma de uma representação não pode ser separada do seu fim e das exigências da sociedade onde aquela determinada linguagem visual é válida". GINZBURG, Carlo. Mitos, emblemas, sinais: morfologia e história. São Paulo: Companhia das Letras, 1989. p. 46-91.

5 BAXANDALL, op. cit., p. 46-47.

${ }^{6}$ FREITAS, Artur. A consolidação do moderno na história da arte do Paraná. Revista de História Regional, p. 84-124, inverno 2003.

7 CAMARGO, Geraldo Leão Veiga. Escolhas abstratas: arte e política no Paraná (1950-1962). Dissertação (Mestrado em História), UFPR, Curitiba, 2002.

${ }^{8}$ Camargo faz uma análise deste período, trabalhando com os conceitos de Bourdieu, onde, de acordo com um número de condições sociais de possibilidades (onde as instâncias políticas, sociais e culturais se inter-relacionam), a produção artística de determinado período é resultado de inúmeras escolhas e lutas localizadas. Partindo das colocações desse autor, consideramos que também Previdi escolheu a sua posição durante a década de 60. CAMARGO, idem.

9 BELTING, Hans. O fim da História da arte: uma revisão dez anos depois. São Paulo. Cosac Naif: 2006. p. 41-50.

${ }^{10}$ CAMARGO, op. cit., p. 5.

${ }^{11}$ Esta obra pertence a um acervo particular, sendo a informação a respeito da representação da Rua Marechal Deodoro fornecida pelo atual dono do quadro, em depoimento concedido em 20 out. 2011 na residência do entrevistado, que solicitou ser mantido em anonimato.

${ }^{12} \mathrm{O}$ artista participou como expositor do Salão Paranaense de 1961, isento de julgamento, pois naquele salão todos os artistas que haviam recebido medalhas de prata e ouro nos salões anteriores seriam contemplados com a exposição de suas obras. Porém, daquele salão em diante, o nome de Previdi desaparece das exposições, inclusive das fichas que catalogam as obras inscritas, o que leva a crer que ele não enviou mais trabalhos a julgamento. Consulta a acervo do Museu de Arte Contemporânea (MAC).

${ }^{13}$ Alcy Xavier fala sobre sua participação no partido Comunista e afirma que sua adesão sempre foi filosófica, nunca ideológica ou proletária, "nunca fui um operário na vida, sempre um pequeno burguês e um anti-nazista." XAVIER. Alcy. Entrevista concedida à Carla Emilia Nascimento em 09 dez. 2011.

${ }^{14}$ Estamos considerando o levantamento de 104 obras, pesquisadas em 14 acervos, constituindo diversos trabalhos (pinturas, desenhos e gravuras) de Previdi, analisados até o presente momento. Destas, as correspondentes à década de 1960 possuem um acentuado destaque para a temática social, trabalhada pelo artista desde a década de 1940. Das obras correspondentes à década 1970 e 80 , é possível dizer que a temática social continua presente em algumas obras, mas não pode ser considerada como a de maior expressividade em número de trabalhos encontrados. 
${ }^{15}$ Segundo Fernando Velloso, até início da década de 50 os alunos da EMBAP concluíam o curso sem ver imagens de obras de arte e quando aparecia alguma reprodução era em preto e branco e muito disputada. VELLOSO, Fernando. Entrevista concedida à Carla Emilia Nascimento em 25 out. 2011.

${ }^{16}$ Apud GINZBURG, op. cit., p. 76.

${ }^{17}$ Polarizando os meios artísticos: criticado o Salão de Belas Artes vários dias antes de sua inauguração oficial. O Dia, Curitiba: 16 dez. 1956.

${ }^{18}$ Paul Garfunkel (1900-1981), um dos artistas inconformados, veio aos jornais da época denunciar o fato de que, de acordo com o regulamento do salão, deveria existir no júri um artista de tendência moderna. Esta reivindicação custou outras páginas de crítica nos jornais, pois foi constatado que a regra realmente existia, porém estava expressa da seguinte forma: "se possível" um membro do júri terá tendência moderna. Extraído de Diário de Notícias de 1958. Sobre a obra de Previdi, está registrada em fotografia na pasta do XIV Salão no acervo documental do Museu de Arte Contemporânea (MAC) do Paraná. Ainda a este respeito, escreve Adalice Araújo no catálogo da $44^{\circ}$ Edição do Salão Paranaense: "Resolvem os artistas, entre premiados com menção honrosa e recusados - Alcy Xavier, Ennio Marques Ferreira, Fernando Velloso, Jair Vicente Mendes, J. Groff, Loio Pérsio, M. Nakahashi, Nilo Previdi, Paul Garfunkel (menção honrosa), Rubens de Haro e Thomas Waltersteiner (menção honrosa) - Expor suas obras no saguão da biblioteca (o que só torna possível graças ao apoio do seu diretor, o prof. Ubaldo Puppi), com o seguinte dístico: 'Pré-julgados do Salão Paranaense de Belas Artes"”. Para citar duas fontes sobre este episódio: Incidente no Salão de Belas Artes do Paraná. Diário de Notícias, Curitiba, s/dia, 1958. Pintores exaltados arrancaram seus quadros (à força) do Salão. Diário do Paraná, Curitiba, 21 dez. 1957.

${ }^{19}$ Consta o nome de Previdi na ficha e no catálogo da I Bienal de São Paulo (1951) com a obra intitulada "Guerra", trabalho realizado com a técnica piroxilina. Catálogo digitalizado disponível em: < http://www.bienal.org.br/FBSP/pt/AHWS/Publicacoes/Paginas/default.aspx>. Acesso em: fev. 2012.

${ }^{20}$ Aracy Amaral delimita no Brasil um período (de 1930 a 70) onde a preocupação do artista em relação à sua função social e de sua arte apresenta-se delineada em três fases distintas. Destacase, para os objetivos deste artigo, a fase correspondente ao período que se estende da Segunda Guerra Mundial até 1956, onde a autora afirma que muitos artistas foram influenciados pelo muralismo mexicano, sendo este também o momento da Criação dos Clubes de Gravura no Brasil e do confronto estabelecido entre os artistas adeptos do realismo e aqueles interessados na tendência abstracionista que adentrava no país a partir da Bienal de 1951. AMARAL, Aracy. Arte para quê? A preocupação social na arte brasileira: 1930-1970. São Paulo: Nobel, 1984.

${ }^{21}$ Em 1990 foi realizada uma exposição com as obras de Previdi, na Galeria de Arte Banestado. De acordo com o currículo apresentado no catálogo da exposição é possível ter uma ideia da inserção do artista em seu meio a partir de suas participações e prêmio adquiridos. No Salão Paranaense de Belas Artes: medalha de prata (1944, 1956 e 1960); menção honrosa (1949); medalha de ouro (1950); medalha de bronze (1952); prêmio de viagem (1953). No Salão de Belas Artes do Clube Concórdia (clube paranaense): medalha de bronze (1951); medalha de prata (s/data). Salão bahiano de Belas Artes: menção honrosa (s/data); Salão Mariano de Pintura: medalha de prata (1954); Grande Olimpíada do Exercito: medalha de bronze (1970); Salão Nacional da Juventude - Bucareste: medalha de prata (s/data). Além de cursos ministrados pelo artista, consta no catálogo outras participações: $1^{\circ}$ Bienal de São Paulo (1951); $4^{\circ}$ Salão Nacional de Arte Moderna/Rio de Janeiro (1955); Exposição de artistas paranaenses na Galeria La Ruche/ São Paulo (1963); $1{ }^{\circ}$ Congresso Pan-americano de Artel Porto Alegre (1957). 
${ }^{22}$ CAMARGO, op. cit., p. 74-84.

${ }^{23}$ FERREIRA, Ennio Marques. Estado do Paraná, Curitiba, 21 dez. 1963

${ }^{24}$ Palavras do próprio artista para o Jornal Leia. Cujo título é "Nilo Previdi: Salão Paranaense foi importação de enlatados", pesquisado na pasta do artista no MAC. Porém, a matéria está incompleta e não fornece data específica.

Artigo recebido em setembro de 2012. Aceito em março de 2013. 